\title{
Current developments and future directions in nuclear waste immobilisation
}

\author{
E. R. Maddrell ${ }^{1} \&$ N. B. Milestone ${ }^{2}$ \\ ${ }^{1}$ Nexia Solutions, Sellafield, UK \\ ${ }^{2}$ Department of Engineering Materials, University of Sheffield, UK
}

\begin{abstract}
Current development work towards novel wasteforms required for the on-going decommissioning of the UK's nuclear facilities is described. A discussion of possible management options for future spent nuclear fuel arisings is given.

Keywords: nuclear, waste, wasteform, cement, glass, ceramic, spent fuel.
\end{abstract}

\section{Introduction}

Two principal technologies are currently employed for the immobilisation of radioactive waste in the United Kingdom: vitrification for high level waste and cementation for various intermediate level waste streams.

Cementation is used in a number of plants on the Sellafield site for the immobilisation of secondary waste streams arising from fuel reprocessing operations such as: metal swarf from the decladding of Magnox reactor fuel; PWR and AGR oxide fuel assembly hulls and ends; ferric hydroxide and other flocs; and barium carbonate slurries. Composite cement systems are used based on binary blends of Ordinary Portland Cement [OPC] with high replacement levels of either Blast Furnace Slag [BFS] for swarf, fuel hulls and slurries, or Pulverised Fly Ash [PFA] for flocs. For fuel assembly components the cement is mixed externally, poured into the drum and allowed to permeate around the metal swarf, whilst for flocs and slurries an internal mixing operation is required to produce a homogeneous blend of liquid waste and cement. Examples of typical immobilised product are shown figure 1. The main objective of cementation is the physical consolidation and stabilisation of the wastes until such a time that they can be moved to safe disposal. 

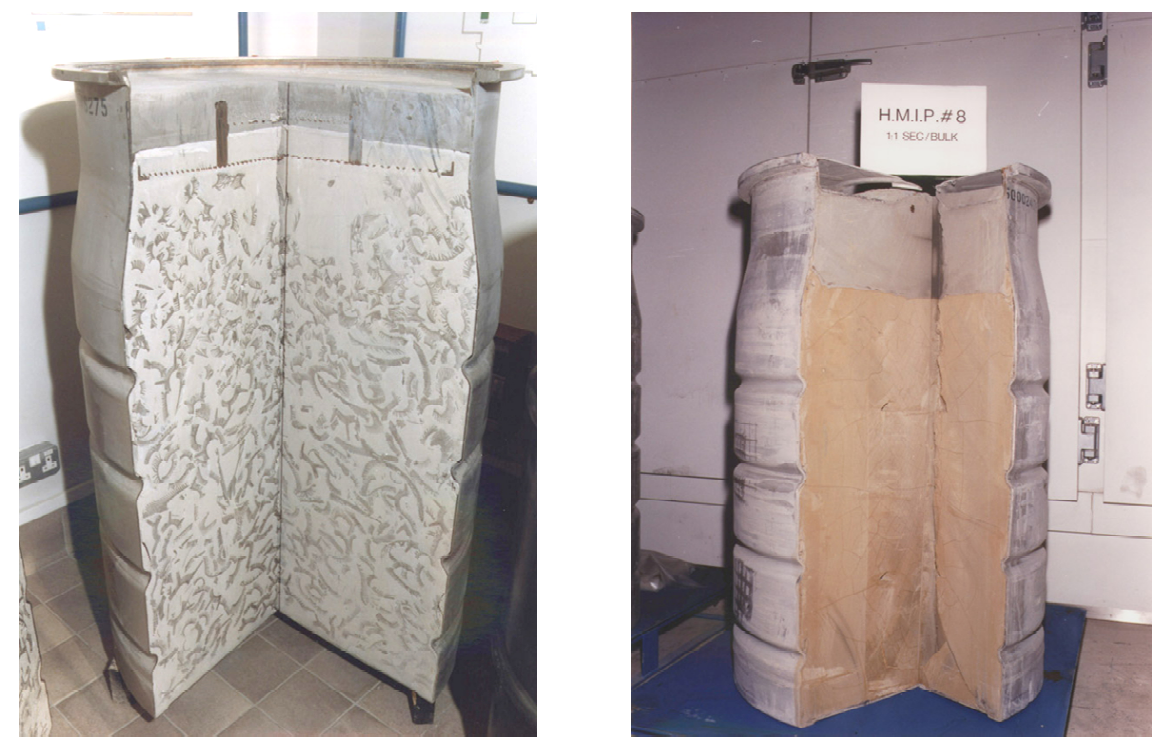

Figure 1: Externally mixed Magnox swarf (left) and internally mixed EARP floc (right).

Vitrification is employed to immobilise the primary highly active [HA] waste stream from fuel reprocessing. This stream is a nitric acid solution containing the radioactive fission products and minor actinides, and inactive fuel additives [e.g. $\mathrm{Al}, \mathrm{Mg}, \mathrm{Fe}]$ that remain after uranium and plutonium have been removed from the dissolved spent fuel by solvent extraction. The HA waste is evaporated to dryness and calcined in a rotary calciner to convert it to oxides. Thereafter, it is incorporated into a mixed alkali borosilicate glass formulation by melting at $1050-1100^{\circ} \mathrm{C}$. Unlike the cementitious wasteforms, the glass is designed to exhibit long term durability.

Whilst these are mature technologies, the progression of clean-up and decommissioning of the UK's nuclear sites is leading to waste streams that are not amenable to immobilisation by these processes. Current work on the development of alternative low and high temperature wasteforms will be reviewed in this paper.

In addition to existing wastes, the maintenance of the UK's nuclear generating capacity, and its possible replacement with new-build reactors, will lead to an additional inventory of spent fuel for which no long term management strategy has been identified. A range of spent fuel management options which the authors believe should be considered in this context will be discussed.

\section{Current developments}

\subsection{Low temperature wasteforms}

Following are brief descriptions of developments in a range of low temperature wasteforms. A more complete discussion of these is given by Milestone [1]. 


\subsubsection{Modified cement formulations}

Whilst the success of OPC/BFS and OPC/PFA cement formulations is undisputed, further improvements are possible. The formulations being used were chosen to control temperature rise but the amount of hydration is limited due to the low amount of cement present. To produce a cement grout that has the necessary fluidity and workability requires the addition of a significant excess of water relative to the optimum amount required for the hydration reactions that occur during cement setting. This residual water is held in pores which can be detrimental to wasteform quality. The use of superplasticisers to improve fluidity is discouraged by the UK Nuclear Industry Radioactive waste EXecutive [NIREX] because of uncertainties over their organic degradation products which may have the ability to complex and mobilise actinide ions. Improved fluidity and workability for a given water to solids ratio could be achieved by using ternary $\mathrm{OPC} / \mathrm{BFS} / \mathrm{PFA}$ cement blends, potentially allowing the water to solids ratio to be reduced from as high as 0.42 to 0.32 . This is still higher than the theoretical amount of $24 \%$ by weight of the cement needed for full hydration. Ternary cements could lead to an improved immobilised product for swarf, hulls and ends. Cement fluidity is crucial to ensure that it can flow evenly through a convoluted network of metallic residues. As decommissioning proceeds, demolition rubble will become a major waste and more fluid cement systems will better enable the rubble to be stabilised for transport to a disposal site. Decontamination prior to demolition will mean that the rubble is low level waste.

\subsubsection{Calcium sulfo-aluminate cements}

One problematic waste stream at Sellafield is the $\mathrm{Cs}$ and $\mathrm{Sr}$ loaded clinoptilolite ion exchange compound. The OPC based cements have an internal pore solution $\mathrm{pH}>12$ and this will attack the zeolite causing the destruction of its framework with concomitant release of Cs. One solution to this reaction requires utilising a completely different cement based on the calcium sulfo-aluminate system. This cement system is extensively used for construction in China and its use for radioactive waste is being examined both there and in the UK. Its formulation is such that the hydration products are free of $\mathrm{Ca}(\mathrm{OH})_{2}$ which reduces the $\mathrm{pH}$ in the internal pore solution to $10-11$ and preserves the integrity of the clinoptilolite. Moreover, the binder formed, ettringite, $3 \mathrm{CaO} \cdot \mathrm{Al}_{2} \mathrm{O}_{3} \cdot 3 \mathrm{CaSO}_{4} \cdot 32 \mathrm{H}_{2} \mathrm{O}$ binds large amounts of water making it unavailable for any ongoing reactions such as corrosion, and it can be extensively substituted making it ideal for immobilisation of a number of toxic species. A further application of this system is for the encapsulation of metallic aluminium wastes which evolve hydrogen in contact with the highly alkaline pore solution of traditional OPC based cements.

\subsubsection{Geopolymers}

An emerging class of low temperature wasteform binder is generically referred to as geopolymers. These are amorphous, 3-dimensional polymeric aluminosilicate networks formed from alkali silicate solution activated glasses such as PFA. A typical atomic structure of a geopolymer is shown in figure 2. In addition to the PFA, the starting materials are 5-8 $\mathrm{M}$ sodium hydroxide and 


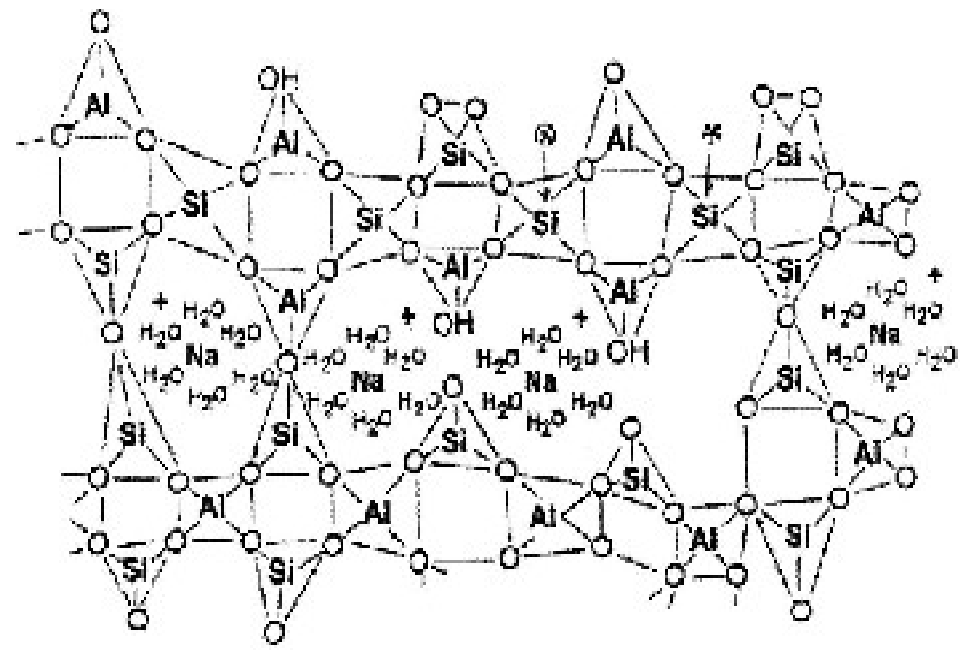

Figure 2: Atomic structure of a geopolymer alkali aluminosilicate binder.

4-5 $\mathrm{M}$ sodium silicate. Clearly this system is highly alkaline, however, in contrast to OPC based systems this does not preclude their use for the immobilisation of zeolites. Rather, the zeolite can be used in place of the PFA component and the Cs remains bound within the aluminosilicate network. Residual water which is not required for the binding phases is contained within pores in the final wasteform and can be lost on heating. Because the binder is not a hydrate it will function at high temperature.

\subsection{High temperature wasteforms}

High temperature wasteforms are preferred to the low temperature alternatives when long term wasteform performance criteria are more stringent. Currently the principal requirement for new high temperature wasteforms is for the immobilisation of wastes and residues containing plutonium and other actinides. These range from wastes that contain plutonium in excess of the level that defines plutonium contaminated material, through to separated plutonium that is surplus to national requirements. Current work is aimed at developing a generic process capable of producing a range of wasteforms tailored to specific waste streams. The process is described in more detail by Scales et al. [2].

\subsubsection{Glass ceramic wasteforms}

The initial driver for the development of a glass ceramic wasteform was a range of highly heterogeneous wastes and residues arising from previous plutonium processing work on the Sellafield site. It is noted that the term glass ceramic is used for convenience to describe a wasteform containing both glass and crystalline phases, and not in the strict Materials Science definition of the term. The principle behind the wasteform is that the miscellaneous and highly variable 
components of the wastes are immobilised in an alumino-borosilicate glass matrix whilst the plutonium partitions into a crystalline zirconolite phase [ideally $\mathrm{CaZrTi}_{2} \mathrm{O}_{7}$ ]. Zirconolite is a naturally occurring mineral which possesses considerable chemical flexibility, thus making it an ideal wasteform phase. In nature, it contains significant quantities of uranium and thorium which have been retained for hundreds of millions of years, despite having experienced aggressive weathering conditions [3]. Consequently, zirconolite has been identified as a key phase for the immobilisation of plutonium and other man made actinides. A typical microstructure for this wasteform, imaged using back scattered electrons in the scanning electron microscope, is shown in figure 3. The light phase is zirconolite, the mid grey phase is calcium fluoride, which occurs in some of the residues, and the background is the glass matrix. The wasteform is highly durable and also demonstrates excellent resistance to the retrieval of plutonium.

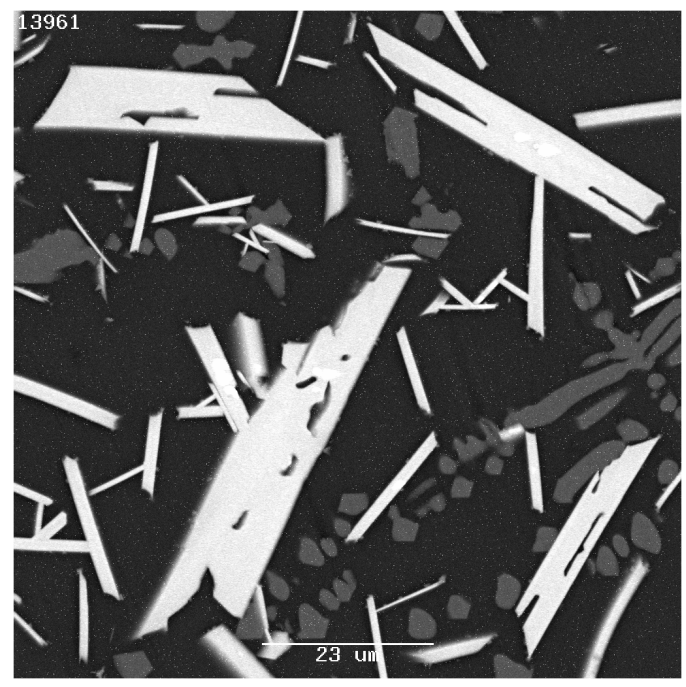

Figure 3: Microstructure of glass ceramic wasteform. Light phase is zirconolite; mid grey phase is calcium fluoride; dark background is glass matrix.

One of the main requirements for processing the residues into the wasteform is to minimise, and preferably avoid, the generation of any secondary wastes. A key means by which this is achieved is through the use of a wholly dry process. The proposed process starts with calcination of the residue and coarse, medium and fine size reduction stages. The fine size reduction will be carried out using an attrition mill and at this stage the residue will be blended with the precursor materials. The output powder will then be granulated to reduce dust and allow it to flow freely through to the consolidation stage.

Consolidation will be achieved through the use of hot isostatic pressing [HIP]. This has been chosen for a number of reasons, including improved flexibility and reduction of volatilisation compared to conventional sintering methods. The HIP 
cans are made to a novel dumbbell design which collapse during HIPping to form regular right cylinders for subsequent ease of handling and storage.

\subsubsection{Ceramics for plutonium immobilisation}

As the development of the above process progressed, it was recognised that there was a wider inventory of actinide wastes at Sellafield and it would be advantageous for the process to be able to handle these. A good example of this is the existence of a quantity of separated $\mathrm{PuO}_{2}$ that, during storage over a number of decades, has become contaminated with chlorine from PVC. Purification of this material such that it would be an acceptable feed to the Sellafield MOx Plant would be uneconomic and hence the material has been designated for immobilisation. The choice of host phase for the plutonium is clearly of great importance.

One candidate phase is the zirconolite used in the glass ceramic. An alternative, developed by the US Department of Energy, [4] is a wasteform based on a related, pyrochlore structured, phase with an approximate target composition of $\left(\mathrm{Ca}_{0.89} \mathrm{Gd}_{0.11}\right)\left(\mathrm{Pu}_{0.22} \mathrm{U}_{0.45} \mathrm{Hf}_{0.22} \mathrm{Gd}_{0.11}\right) \mathrm{Ti}_{2} \mathrm{O}_{7}$. This wasteform was referred to as pyrochlore but the closest mineral analogue is actually betafite, ideally $\mathrm{CaUTi}_{2} \mathrm{O}_{7}$. On the basis of data from natural analogues, zirconolite has been shown to exhibit superior long term resistance to alteration than betafite. It has been demonstrated that both of these phases can be produced using the dry processing line developed for the glass ceramic wasteform.

An important factor behind the definition of the US DoE wasteform was the use of multiple barriers to prevent criticality: Gd and Hf both act as neutron poisons, whilst the addition of depleted uranium dilutes the fissile U-235 that the $\mathrm{Pu}-239$ will have all decayed to within 250,000 years. This criticality control philosophy was based on the assumption that no credit could be afforded to the long term durability of the wasteform. The approach towards criticality control that will be taken within the UK is currently under discussion.

It has been suggested that a weakness of these titanate mixed oxide wasteforms is that they become amorphous as alpha decay damage accumulates, and this will lead to a deterioration in their leach resistance. Consequently, there has been much attention in recent years directed at zirconia based wasteforms such as zirconate pyrochlores $\left[\mathrm{Gd}_{2} \mathrm{Zr}_{2} \mathrm{O}_{7}\right]$ [5] and cubic zirconia solid solutions $\left[(\mathrm{Zr}, \mathrm{Y}, \mathrm{Pu}) \mathrm{O}_{2-\mathrm{x}}\right]$ which remain crystalline even after extensive radiation damage. It has recently been demonstrated, however, [6] that amorphisation of titanate wasteforms does not lead to a significant increase in leach rates and hence the importance of resistance to radiation damage may not be as great as claimed. Zirconia based wasteforms also have less chemical flexibility than the titanates and require significantly higher consolidation temperatures, making them unsuitable for the process under development. We are also evaluating the potential of other phases for plutonium immobilisation such as britholite $\left[\mathrm{Ca}_{2} \mathrm{Gd}_{8}\left(\mathrm{SiO}_{4}\right)_{6} \mathrm{O}_{2}\right]$ and kosnarite $\left[\mathrm{NaZr}_{2}\left(\mathrm{PO}_{4}\right)_{3}\right]$.

\subsubsection{Ceramics for MOx residues.}

Residues from the Sellafield MOx Plant are predominantly a solid solution of $\mathrm{PuO}_{2}$ in $\mathrm{UO}_{2}$. From the brief discussion of wasteforms for separated plutonium 
above, it can be seen that the US DoE pyrochlore formulation is clearly a favoured wasteform in that it facilitates much higher waste loadings than zirconolite. Again, the process initially described is amenable to the immobilisation of MOx residues.

\section{Future directions - to immobilise or to isolate?}

The maintenance of the UK's current nuclear generating base is the subject of significant debate and Government review [7]. It is axiomatic that management options for future arisings of spent fuel are included in this discussion. Whilst the existing strategy for spent fuel management in the UK is based on reprocessing, worldwide there is a growing move towards a once-through fuel cycle followed by direct disposal of the spent fuel. The difference between these two options exemplifies the two competing philosophies at the heart of nuclear waste management: to immobilise or to isolate? Immobilisation requires the conversion of the waste into a wasteform from which the hazardous nuclides cannot be leached. Isolation relies on a combination of engineered and geological barriers that retard the movement of nuclides back to the biosphere - central to this philosophy is that the return of a nuclide to the biosphere is controlled by its solubility in groundwater and that this is independent of the wasteform.

Management of spent fuel is not limited to these two options and the following is a brief discussion of a wider range of technologies that might be considered with a qualitative description of their relative advantages and disadvantages. The options are arranged in increasing order of the complexity of processing involved. A key factor, upon which public consensus should be sought, is whether the environmental impact of disposal over future millennia should satisfy criteria defined today as being an acceptable hazard, or whether society should strive for the best immobilisation and disposal combination possible. In the discussion, an effluent is taken to be a by-product that is discharged to the environment whilst a waste is disposed of to a repository.

\subsection{Direct disposal}

This is the embodiment of the isolation option and is the simplest concept in that, after a period of cooling, spent fuel is put into an overpack and sent to a repository. Economically, fuel processing costs are avoided, which is attractive, although this benefit will be eroded by the cost of the exotic alloys used for overpacking and other engineered barriers. Although the fuel is not processed, it is claimed that the $\mathrm{UO}_{2}$ matrix of the fuel is an effective wasteform. Nevertheless, long lived fission products such as Caesium-135 (half-life 2.3 million years) and Iodine-129 (half-life 15.7 million years) are not effectively immobilised by $\mathrm{UO}_{2}$ [8] and have high solubilities in groundwater. Many environmental models of direct disposal show that a major dose contributor is I-129, [9] and that this dose occurs within the first half life of I-129; hence the 'decay' of I-129 is due to it being flushed from the repository system into the sea. Given that in the existing reprocessing scenario I-129 is discharged directly 
to sea - in accordance with IAEA recommendations - it might be argued that this dose to future societies due to I-129 is incurred needlessly.

\subsection{Spent fuel conditioning}

If reprocessing of spent fuel to recover plutonium for future use is not necessary, it might be argued that direct disposal is a satisfactory end point. However, spent fuel is not an optimised wasteform. A fuel processing cycle can be developed in which uranium only is extracted from the dissolved spent fuel and the remainder, comprising fission products and all transuranic elements, is immobilised in an appropriate wasteform. The high plutonium content of this waste stream would require the use of a wasteform such as the titanate ceramic Synroc, and this would be demonstrably more proliferation resistant than the original spent fuel. The use of titanate ceramics as a wasteform challenges the above notion that wasteform durability is unimportant to the long term environmental impact of waste disposal. McGlinn [10] has confirmed that elemental concentrations in leachates from titanate ceramics are below their solubility limit, which indicates that superior wasteforms can reduce the environmental impact of disposal. In this scenario the I-129 would be discharged directly to sea, however, we are also evaluating wasteforms for the immobilisation of iodine.

\subsection{Reprocessing using PUREX technology}

A continuation of the UK's current reprocessing strategy requires that plutonium is viewed as a future asset. There are a number of enhancements that could be made such as single cycle solvent extraction, minimisation of effluents, the reduction of low and intermediate level waste and the use of improved wasteforms such as titanate ceramics.

\subsection{Novel non-aqueous reprocessing technology}

One argument against existing PUREX reprocessing technology is that aqueous processes inevitably lead to effluent discharges and this has led to interest in non-aqueous technologies to avoid effluents. A prominent example of a nonaqueous fuel processing technology is commonly referred to as pyroprocessing. This involves electrochemical separations of the spent fuel using a molten $\mathrm{KCl}$ $\mathrm{LiCl}$ electrolyte. Whilst this may be successful in eliminating effluents, the resulting waste stream is not readily amenable to immobilisation, leading to low waste loadings and increased volumes of a less than optimum wasteform.

This raises the question of whether today's society would favour an effluent free technology combined with a poor wasteform, potentially leading to a greater long term environmental impact; or a safe level of effluent - rapidly dispersed in the oceans - combined with a wasteform of maximum durability.

\subsection{Enhanced separation and selective immobilisation}

This technology further supports the position that the durability of the wasteform is important in the disposal scenario. Moreover, it extends this to the view that 
certain components of the high level waste stream are best immobilised using different wasteforms. Enhanced separation cycles are used and the waste streams are processed into the preferred wasteforms. Whilst this is viewed as further reducing the environmental impact in the disposal scenario, this benefit must be assessed against increased operational hazards such as dose to plant operators.

\subsection{Partitioning and transmutation}

To many people, this represents the holy grail of nuclear waste management. Rather than dispose of a radioactive waste, the key long lived nuclides are separated by chemical means and made into targets for irradiation. In principle, irradiation converts long lived radioactive nuclides into stable ones that can be safely disposed of. Short lived nuclides are simply allowed to decay before disposal as inactive waste. In practice there are some fundamental obstacles, for example, the nuclear physics can mean that transmutation half-lives are long and multiple irradiations are required before a particular nuclide can be destroyed. Also, additional complications arise for certain elements in the spent fuel. One example is that the destruction of the Cs-135 isotope is accompanied by conversion of inactive Cs-133 - from which it is inseparable - to further Cs-135.

\section{Conclusions}

The development of new waste immobilisation technologies in support of the decommissioning of the UK's nuclear sites has been described. Options for the management of future arisings of spent nuclear fuel, for which no long term strategy has been defined, are discussed. It is recommended that a more detailed, quantitative assessment of these is conducted.

\section{Acknowledgements}

The authors acknowledge the Nuclear Decommissioning Authority and British Nuclear Group for funding much of the work described in this paper. The views expressed by the authors do not necessarily reflect UK Government policy.

\section{References}

[1] Milestone, N.B., Reactions in cement encapsulated nuclear wastes: need for toolbox of different cement types. Advances in Applied Ceramics, 105(1), pp. 13-20, 2006.

[2] Scales, C.R., Maddrell, E.R., Gawthorpe, N., Day, R.A., Begg, B.D., Moricca, S.S. and Stewart, M.W.A., A flexible process for the immobilisation of plutonium containing wastes. Proceedings of Global 2005, Paper No. 249.

[3] Lumpkin, G.R., Day, R.A., McGlinn, P.J., Payne, T.E., Giere, R. and Williams, C.T., Investigation of the long-term performance of betafite and zirconolite in hydrothermal veins from Adamello, Italy. Scientific Basis 
for Nuclear Waste Management XXII, eds. D.J. Wronkiewicz \& J.H. Lee, MRS Symposium Proceedings 556. pp. 793-800, 1999.

[4] Ebbinghaus, B.B., Armantrout, G.A., Gray, L., Herman, C.C., Shaw, H.F. and Van Konyenburg, R.A., Plutonium immobilization project baseline formulation. LLNL report UCRL-ID-133089, 2000.

[5] Ewing, R.C., Weber, W.J. and Lian, J., Nuclear waste disposal pyrochlore $\left(\mathrm{A}_{2} \mathrm{~B}_{2} \mathrm{O}_{7}\right)$ : Nuclear waste form for the immobilization of plutonium and "minor" actinides. J. App. Phys., 95(11), pp. 5949-5971, 2004.

[6] Strachan D.M., Scheele, R.D., Icenhower, J.P., Buck, E.C., Kozelisky, A.E., Sell, R.L., Elovich, R.J. and Buchmiller W.C., Radiation damage effects in candidate ceramics for plutonium immobilization: final report. PNNL-14588, Pacific Northwest National Laboratory, Richland, WA. 2004.

[7] Our energy challenge; securing clean affordable energy for the long-term. UK DTI Energy review consultation document. Jan 2006.

http://www.dti.gov.uk/energy/review/energy_review_consultation.pdf

[8] Poinssot, C., Jegou, C., Toulhoat, P., Piron, J.-P. and Gras, J.-M., A new approach to the RN source term for spent nuclear fuel under geological disposal conditions. Scientific Basis for Nuclear Waste Management $X X I V$, eds. K.P. Hart \& G.R. Lumpkin, MRS Symposium Proceedings 663. pp. 469-76, 2001.

[9] Wilson, M.L., Swift, P.N., McNeish, J.A. and Sevougian, S.D., Total system performance assessment for the Yucca Mountain site. Scientific Basis for Nuclear Waste Management XXV, eds. B.P. McGrail \& G.A. Cragnolino, MRS Symposium Proceedings 713. pp. 153-64, 2002.

[10] McGlinn, P.J., Personal communication, 31 ${ }^{\text {st }}$ Jan. 2006, Australian Nuclear Science and Technology Organisation. 